\title{
Erratum
}

\section{Erratum to "Regional Stability Analysis of Red Clay Slope Based on Different Failure Modes: A Case Study in Taizaifu Area, Fukuoka"}

\author{
Fang Wei $\mathbb{D}$ \\ School of Traffic and Transportation Engineering, Changsha University of Science and Technology, Changsha, \\ Hunan 410004, China \\ Correspondence should be addressed to Fang Wei; fangwei5642366@163.com
}

Received 17 May 2020; Accepted 28 May 2020; Published 16 June 2021

Copyright (C) 2021 Fang Wei. This is an open access article distributed under the Creative Commons Attribution License, which permits unrestricted use, distribution, and reproduction in any medium, provided the original work is properly cited.

In the article titled "Regional Stability Analysis of Red Clay Slope Based on Different Failure Modes: A Case Study in
Taizaifu Area, Fukuoka" [1], there was an error in the legend of Figure 11(b). The corrected figure should be as follows:

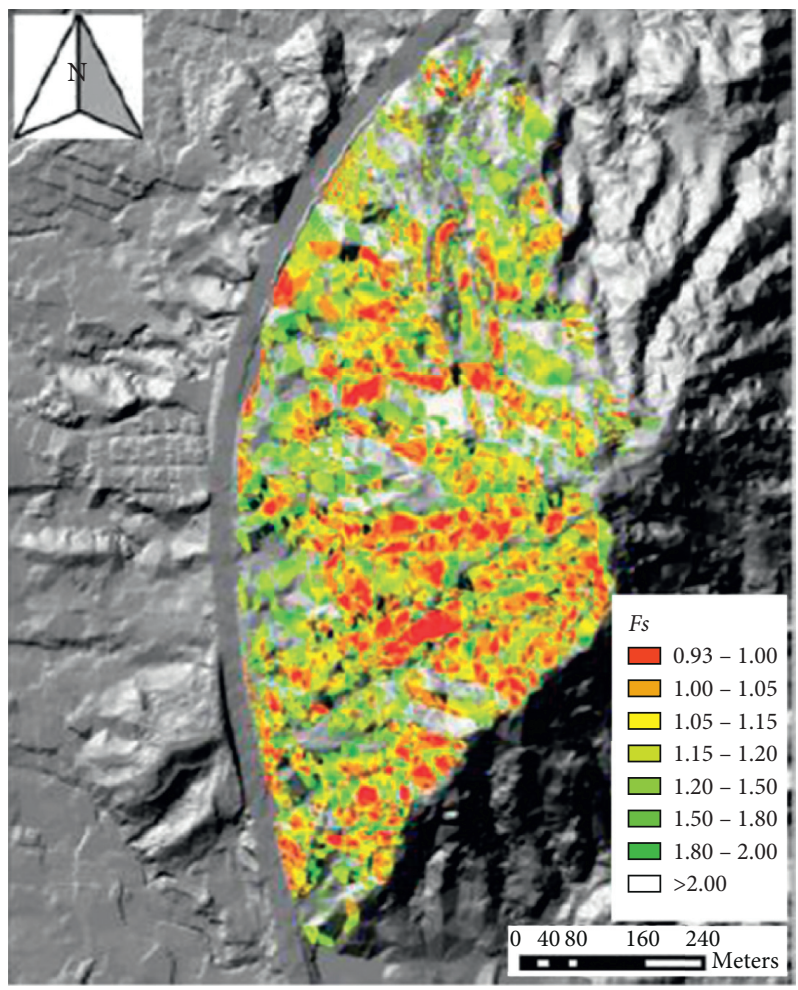

FIGURE 11: Maps of regional slope stability: (a) integral sliding; (b) planar sliding; (c) landslide occurrence. 
The error was introduced during the production process of the article, and the publisher apologises for causing this error in the article.

\section{References}

[1] F. Wei, "Regional Stability Analysis of Red Clay Slope Based on Different Failure Modes: A Case Study in Taizaifu Area, Fukuoka," Advances in Civil Engineering, vol. 2019, Article ID 1269832, 11 pages, 2019. 